Telemedicine (TM) has been a rapidly growing method of providing health care in different medical settings. Using technology to provide healthcare at a distance can be very helpful in improving access to health care in rural areas, providing immediate medical care when needed and reducing the cost of delivering medical care. Telemedicine patients often report positive experiences, given the speed of access, time saved, and the ability to stay in contact with healthcare providers. These virtual visits may help improve compliance with followup consultations by reducing the barriers of distance and transportation.

Telemedicine may also be used in providing service coverage when the medical provider becomes suddenly unavailable due to any kind of emergency (medical, social).

We present our experience in using TM as a tool for provider coverage in an immediate need situation as an alternative to rescheduling patent appointments

We evaluated families choice in accepting a TM visit in a pediatric endocrinology clinic as an alternative to rescheduling appointments with the provider who suddenly became unavailable due to a medical emergency. The families were educated about the TM visit and were given the option to participate. The TM visits were conducted between two medical practices Fourteen families were offered a TM visit when their physician was not available to conduct the visit. Six families (42\%) agreed to participate in the TM visits, four families (66\%) showed up. All cases of TM visits were follow up visits to review the medical condition, growth parameters, laboratory test results and discuss the management plan.

Satisfaction rate regarding the TM visit was obtained at the end of the visit, this TM visit was the first experience for all families, all of the participating families (100\%) expressed satisfaction with the visit and stated that they would participate in TM visits in the future, if offered.

Families who declined the TM visit were rescheduled for traditional physician visits with the same provider or another provider within the same group.

Telemedicine can offer a fast and practical solution to provide coverage for physicians when there is a sudden immediate need. Rescheduling may not be well received from some patients so having the TM option is a futuristic way of covering health care delivery. Patients should be informed about the TM visit structure prior to their participation. Conducting TM visit when patients are at home may increase acceptance and participation.

\section{A CASE OF INTENTIONAL VIRILIZATION OF A YOUNG FEMALE TODDLER. THE MEDICAL AND LEGAL CONSEQUENCES}

Michael Yafi Yafi* ${ }^{*}$ Katherine Velez, Rebecca Girardet. University of Texas Health Science Center at Houston

\subsection{6/archdischild-2021-europaediatrics.201}

A five- months- old female, born with normal female genitalia, developed clitoromegaly. Physical examination showed a $3 \mathrm{~cm}$ length $\mathrm{x} 0.8 \mathrm{~cm}$ width clitoris and Tanner 2 pubic hair/1 breasts.

She lived with her biological grandmother and step grandfather. The grandmother worked, while step grandfather was the primary caregiver, during the day.
Laboratory testing showed very elevated levels of both total and free testosterone (above $1500 \mathrm{ng} / \mathrm{dL}: 52 \mathrm{nmol} / \mathrm{L}$ ) $(402.5$ $\mathrm{pg} / \mathrm{mL}$ ), respectively $\mathrm{LH}$ and FSH levels were pre-pubertal, 17-hydroxyprogesterone, 11 Deoxycorticosterone, DHEA, $\mathrm{ACTH}$, cortisol, anti-mullerian hormone $(\mathrm{AMH})$, and tumor markers (HCG, AFP) levels were normal.

Karyotype was 46XX with FISH negative for SRY. Pelvic MRI showed a uterus with no pelvic masses.

When asked about possible exposure to hormones, the step grandfather, aged

52 years, stated that he was on testosterone creams and that he was probably accidentally exposed her by holding her after rubbing the cream on his shoulder. Education as to how to avoid exposure was provided. Testosterone levels dropped to $158 \mathrm{ng} / \mathrm{dL}(5.4 \mathrm{nmol} / \mathrm{L})$ by 3 months after the first visit but went up few months later to $975 \mathrm{ng} / \mathrm{dL}(33.8 \mathrm{nmol} / \mathrm{L})$ with growth acceleration, clitoral growth of $4.5 \mathrm{~cm}$ in length and labial fusion, muscular appearance and acne.

At this time, she was hospitalized for 6 weeks and Children's Protective Services were contacted. The step grandfather was not allowed to see her.

The testosterone dropped to a normal level of $3.8 \mathrm{ng} / \mathrm{dL}$ $(0.13 \mathrm{nmol} / \mathrm{L})$. The child was later was adopted by extended family members.

The child's testosterone level remained undetectable after discharge but her voice remained very deep. She went through clitoroplasty. Her clitoral size was reduced surgically to 2.5 $\mathrm{cm}$ length. Her acne has resolved and her mood was pleasant.

Law enforcement investigation of the step-grandfather revealed several containers of testosterone products in the home, as well as pornography and multiple used condoms. He was arrested and convicted of committing serious bodily injury to a child, and was sentenced to 20 years in prison.

Discussion Virilization of pre-pubertal girls should prompt a detailed medical work up to rule out a virilization form of Congenital Adrenal Hyperplasia (CAH) or androgen producing tumors. If medical pathologies are ruled out, environmental exposure to testosterone should be suspected.

While all of the reported pediatric virilization cases due to hormonal exposure were accidental, this is case is the first report of intentional and criminal exposure.

\section{CENTRAL PRECOCIOUS PUBERTY IN DIZYGOTIC TWIN SISTERS CAUSED BY MUTATION IN THE MAKORIN RING FINGER PROTEIN 3 GENE}

Marija Požgaj Šepec*, Lavinia La Grasta Sabolić, Magdalena Avbelj Stefanija, Jernej Kovač, Gordana Stipančić. Department of Pediatrics, Sestre milosrdnice University Hospital Centre, Zagreb, Croatia

\subsection{6/archdischild-2021-europaediatrics.202}

Background Central precocious puberty (CPP) is defined by gonadotrophin-dependent development of secondary sex characteristics before the age of 8 in girls and 9 years in boys. Approximately $25 \%$ of CPP cases are familial, but its genetic cause often remains unknown. Mutations in makorin RING finger protein 3 gene $(\mathrm{MKRN})$ are a common cause of familial CPP, being identified in 33-46\% of familial cases. We describe dizygotic twin sisters diagnosed with CPP and treated with gonadotrophin-releasing hormone agonists analog (GnRHa), in whom genetic analysis revealed the cause for CPP. 
Case Presentation A 6.4 year old girl presented with acne, pubic hair and body odour.

Diagnosis of CPP was performed on the basis of clinical signs of central puberty (breast Tanner 2 and pubic hair Tanner 2), increased basal gonadotrophine hormones (LH $4.6 \mathrm{IU} /$ L, FSH $3.7 \mathrm{IU} / \mathrm{L}, \mathrm{E} 2109 \mathrm{pmol} / \mathrm{L}$ ) and growth spurt (height on 1.6 SDS). Her bone age was assessed to be 7 years.

Brain Magnetic Resonance (MRI) did not disclose any abnormality. Treatment with GnRHa was given subcutaneously once a month (triptorelin in a dose

$3.75 \mathrm{mg}$ ). Girl's dizygotic twin sister developed signs of puberty at the age of 8 years. At presentation, she had breast Tanner 3 and pubic hair Tanner 1. Her bone age was 8.6 years, her height was on 0.8 SDS. Laboratory assessment confirmed CPP (LH 1.07 IU/L, FSH 3.9 IU/L, E2 187 pmol/L ) and after additional endocrinological and neuroradiological work-up, suppression of CPP started. Precocious puberty was well controlled by pharmacological therapy and both sisters reached their final height $(163.8$ and $159.1 \mathrm{~cm})$ in accordance with midparental height (MPH $165 \mathrm{~cm}, 0.6 \mathrm{SDS}$ ).

As CPP was diagnosed in both dyzygotic twin sisters, we sought for a genetic cause.

Coding regions of the MKRN3 gene and exon-intron boundaries were analyzed using Sanger sequencing. Pathologic heterozygous variant NM_005664.3:3:c.475_476insC (NP_005655.1:p.Ala162Glyfs) of MKRN3 gene was identified in both siblings.

Conclusion We want to highlight the importance of genetic analysis in cases od familial CPP, providing grounds for genetic counseling in later life.

\section{TRANSIT BILATERAL CATARACT IN TWO NEWLY DIAGNOSED TYPE 1 DIABETES MELLITES IN PEDIATRIC POPULATION}

Marko Simunovic*, Martina Paradzik, Roko Skrabic, Kajo Bucan, Veselin Skrabic. University Hospital of Split

\subsection{6/archdischild-2021-europaediatrics.203}

Introduction Cataract is a rare manifestation of ocular complication at an early phase of type 1 diabetes mellites (T1DM) in the pediatric population. The prevalence of early diabetic cataract in the population varies between 0.7 and $3.4 \%$ of children and adolescents with T1DM. The occurrence of diabetic cataract in most pediatric patients is the first sign of T1DM or occurs within 6 months of diagnosis of T1DM.

Case 1: A 15.9-year-old girl presented with newly diagnosed T1DM with hyperglycemia of $21.6 \mathrm{mmol} / \mathrm{L}$, ketonemia of $6.3 \mathrm{mmol} / \mathrm{L}$, significant ketonuria and glucosuria, but without diabetic ketoacidosis ( $\mathrm{pH} 7.344$, bicarbonate $17.1 \mathrm{mmol} /$ L). She had a 2 months history of polydipsia, polyuria and 7 $\mathrm{kg}$ weight loss. Laboratory findings at admission include: haemoglobin A1c (HbA1c) of 16.9\%, C-peptide of $0.2 \mathrm{nmol} / \mathrm{L}$ and positive GAD-65, ICA-512, and IA-2 antibodies. She was treated with intensive insulin basal/bolus regimen.

On 7-day of the hospitalization patient started to have blurriness of vision. Ophthalmological examination showed 0.9 vision on both eyes and examination on the biomicroscope indicated bilateral center nuclear cataract. On 14-day almost complete transparency of lens was observed, with complete visual acuity recovery.
Case 2: A 13.53-year-old girl was admitted with 3 months history of polydipsia, polyuria, nycturia and $11 \mathrm{~kg}$ weight loss. In initial laboratory evaluation T1DM was confirmed (hyperglycemia of $26.9 \mathrm{mmol} / \mathrm{L}$, ketonemia of $5.1 \mathrm{mmol} / \mathrm{L}$, significant ketonuria and glucosuria, HbA1c 17.1\%, C-peptide $0.18 \mathrm{nmol} / \mathrm{L}$ and positive antibodies), but without sings of ketoacidosis ( $\mathrm{pH} 7.411$, bicarbonate $21.6 \mathrm{mmol} / \mathrm{L}$ ). Treatment with basal/bolus regimen was started. On 9-day of the hospitalization patient began to complain of impaired vision. Biomicroscope examination showed bilateral center nuclear cataract with visual acuity of 0.8 on both eyes. On 25-day patient had normal visual acuity, with full transparency of lens.

Conclusion Early diabetic cataract although a rare complication of T1DM population, requires an initial screening as well as continuous surveillance as a measure of prevention since it is the leading causes of visual impairment in pediatric T1DM patients, especially in patients with long-term symptoms of T1DM and high levels of HbA1c. Additional studies are needed to further explain the etiological cause and therefore improve the prevention and treatment of diabetic cataract in population of children and adolescents.

\section{CASE REPORT OF RESISTANCE TO THYROID HORMONE WUTH MUTATION TO THE THYROID $\beta$ RECEPTOR GENE}

Lizaveta Collins*, Saadia Rao, Helan Shing, Beth McLean. East Suffolk And North Essex NHS Foundation Trust Colchester Hospital

10.1136/archdischild-2021-europaediatrics.204

Background Thyroid hormones are important for energy metabolism, the metabolism of nutrients and inorganic ions, thermogenesis, and for stimulation of growth and development of various tissues Case The baby girl, was born at 39/40 uncomplicated pregnancy, presented to prolong jaundice clinic at 19th days old, Newborn bloodspot screening at 5 days was normal. She sleeps a lot and often cries when tired.

Developmentally appropriate The blood test showed the TSH $(35.7 \mathrm{mIU} / \mathrm{L})$ and FT4 $(2.87 \mathrm{mlU} / \mathrm{L})$. Her thyroid function was monitors and remained the same for 3 months However at 4 months of age she had TSH $1.2 \mathrm{mlU} / \mathrm{L}$ and T4 $25.4 \mathrm{mlU} / \mathrm{L}$, Free T3 $16.3 \mathrm{mlU} / \mathrm{L}$ She had the fluorescent sequencing analysis which showed Thyroid hormone resistance (RTH). Heterozygous mutation in TR beta - c.1286G >A (p. Arg429GIn). The diagnosis helps to provide the genetic counselling for the family.

Conclusion Resistance to thyroid hormone (RTH) 1:40,000 live births is a rare inherited syndrome characterized by diminished response of the target tissue to thyroid hormone caused, in the majority of cases, by mutation of the thyroid hormone receptor beta (THR $\beta$ ) gene. The diagnosis of RTH is challenging for the clinician. It should be considered in a patient presenting with unexplained elevated serum free T4 (fT4), unsuppressed TSH levels and decreased serum free T4/T3 ratio. The treatment decision depends on the individual characteristics of each patient. Patients with hypothyroid and hyperthyroid symptoms may require treatment with thyroid hormone and with agents such as beta blockers, antithyroid drugs and thyroid hormone analogues 